\title{
Tricogranuloma, o granuloma del peluquero, en las manos
}

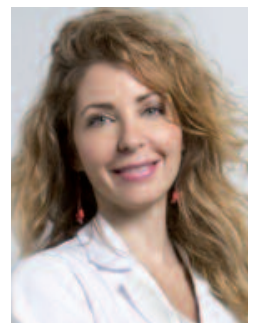

Elena González-Guerra Médico adjunto del Servicio de Dermatología. Hospital Universitario Clínico San Carlos. Madrid. Profesora asociada de Dermatología Médico-Quirúrgica y Venereología (Ciencias de la Salud). Departamento de Medicina. Universidad Complutense de Madrid. Directora del Máster en Dermofarmacia y Formulación Cosmética. Universidad Internacional de la Rioja (UNIR).

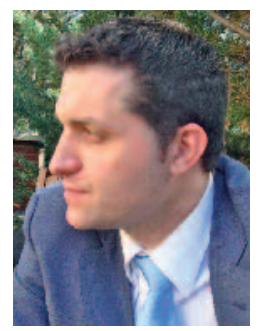

Alejandro González-Guerra Técnico especialista en Emergencias Sanitarias.

Tutor de prácticas de formación continuada del personal sanitario. SUMMA 112. Madrid.
Mi paciente es un varón de 45 años de edad dedicado, como él dice, al estilismo capilar masculino o, lo que es lo mismo, peluquero de caballeros. Acude a consulta sumamente preocupado porque, desde hace seis meses, le salen periódicamente unos abultamientos en algunas zonas de las manos, fundamentalmente, entre los dedos y, a veces, en las palmas. Siempre aparecen en los mismos lugares, con cierto dolor, inflamación y calor, supurando durante dos o tres días, y calmándose poco después. En alguno de esos episodios, ha visto fragmentos oscuros, que no sabe identificar y que ha intentado eliminar haciendo presión sobre el pus. Por su cuenta, se ha aplicado un antiverrugas de la farmacia (con ácido salicílico), con lo que, en lugar de mejorar, ha empeorado. Su ansiedad es intensa, tanto por el proceso en sí como por la repercusión en su actividad laboral, pues, cuando la piel supura, no puede trabajar y sus clientes se molestan. Por lo demás, es un paciente fumador de 20 cigarrillos al día sin antecedentes patológicos de interés.

En la exploración física cutánea, pude ver tanto en la mano derecha como en la izquierda varias lesiones situadas en el espacio interdigital del primero y segundo dedos y en la palma de la mano derecha. Presentaban eritema, cierto edema, supuración y trayectos cicatriciales (fig. 1) junto a costras y cicatrices puntuales (fig. 2). Con la presión lateral, dolorosa, se expulsaba un material serohemático.

Mi planteamiento diagnóstico inicial fue el de tricogranuloma, pero, al no evidenciar pelos a simple vista ni con el dermatoscopio y ante la duda de otra enfermedad, decidí hacer una biopsia-extirpación de una de las lesiones. En el estudio anatomopatológico, pude ver, en el seno de una reacción inflamatoria formada por linfocitos, histiocitos y células gigantes multinucleadas, varias formaciones pilosas y restos de material queratósico (fig. 3), confirmándose el diagnóstico de tricogranuloma, quiste pilonidal interdigital o granuloma del peluquero o, en otras publicaciones, mano de barbero.

El proceso es, en definitiva, una reacción a cuerpo extraño debida a la entrada de fragmentos de pelo cortos y afilados en la piel. Precisamente, esas características del cabello cortado hacen que sea más frecuente en los peluqueros de hombres que de mujeres ${ }^{1,2}$. Si la evolución es prolongada, ante nuevos pelos introducidos y nuevas inflamaciones localizadas, se pueden generar fístulas y cicatrices, semejantes a las de los quistes pilonidales de otras localizaciones. Existen algunas menos típicas, como pueden ser las de los pies en los peluqueros que andan con sandalias o con los pies 


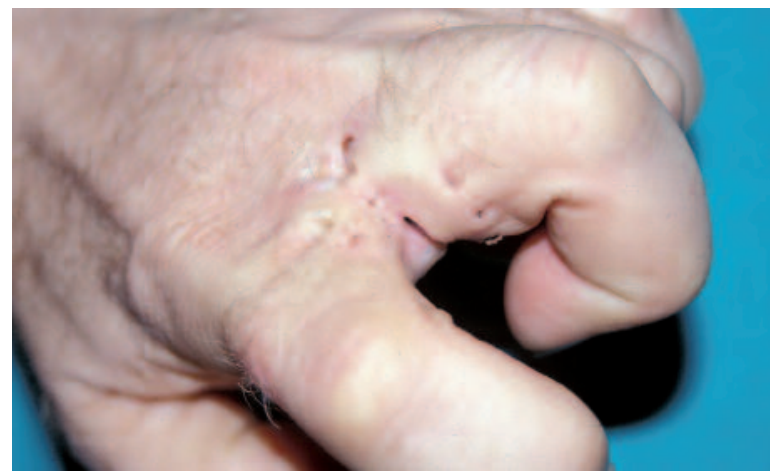

Figura 1. Lesiones supurativas fistulosas y cicatriciales en el espacio interdigital del primero y segundo dedos de la mano izquierda.

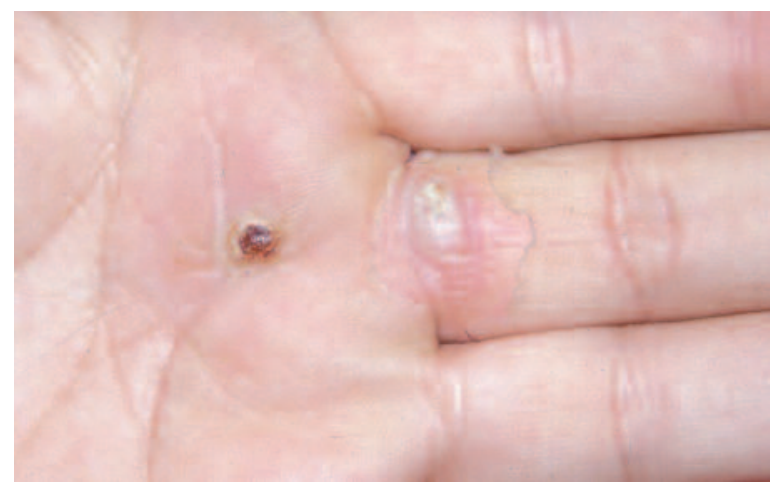

Figura 2. Lesión eritematosa, costrosa y cicatricial en la palma de la mano.

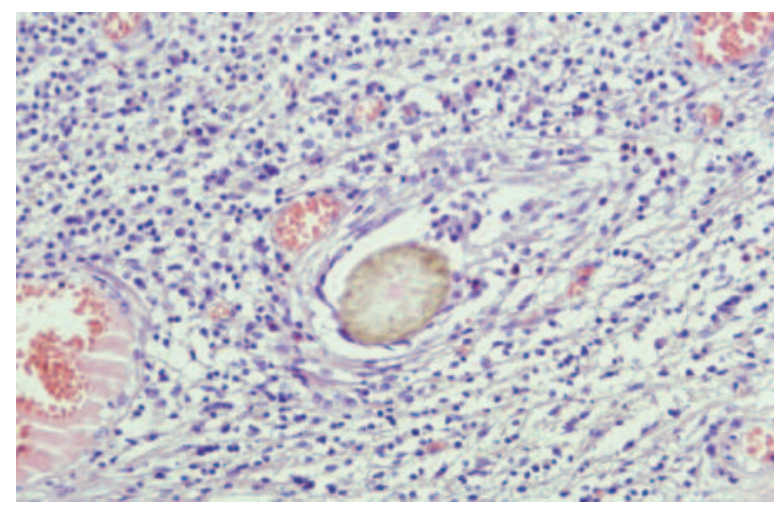

Figura 3. Reacción inflamatoria de linfocitos, histiocitos y células gigantes multinucleadas, con formaciones pilosas y material queratósico. semidesnudos ${ }^{3}$. Es rara la afectación subungueal, salvo cuando existe onicólisis previa, como en el caso de Hogan ${ }^{4}$. Del mismo modo, es rara la localización en los pulpejos, que suele deberse a la existencia de alteraciones previas y concomitantes, como ocurrió en el caso de Craveiro-Lopes et $a l .{ }^{5}$, de una paciente con esclerosis sistémica y tricogranuloma facilitado por las ulceraciones distales de los dedos.

El tricogranuloma del peluquero es una afección escasamente descrita en la literatura, lo que no nos permite tener datos de su prevalencia real. No obstante, el hecho de que la mayoría de los peluqueros conozcan el proceso y su naturaleza benigna hace pensar que ellos mismos se diagnostican y tratan eliminando con unas pinzas los pelos visibles. De la misma opinión son la mayoría de los autores que refieren casos individuales ${ }^{6}$.

En la misma línea estuvo el tratamiento que efectuamos: antisépticos, extracción de todos los cabellos visibles y una limpieza quirúrgica superficial. En sucesivas revisiones, se hicieron visibles algunos pelos inicialmente escondidos, que fueron extraídos mecánicamente hasta la curación del cuadro. A partir de entonces, la prevención con la protección adecuada quedó en manos de mi paciente, al parecer, ya que no acudió más, con buenos resultados.

\section{BIBLIOGRAFÍA}

1. Grant I, Mahaffey PJ. Pilonidal sinus of the finger pulp. J Hand Surg Br. 2001;26(5):490-1.

2. Nikolaou VA, Stavropoulos PG, Avgerinou G, Katsambas AD. Multiple trichogranulomas in a hairdresser. Int J Dermatol. 2006;45(8):993-4.

3. De Argila Fernández-Durán D. Una mujer de 47 años, vecina de Puebla de la Calzada. Más Dermatol. 2007;(1):15-6.

4. Hogan DJ. Subungual trichogranuloma in a hairdresser. Cutis. 1988;42(2):105-6.

5. Craveiro-Lopes B, Grant I, Adler Al. Trichogranuloma in a hairdresser with systemic sclerosis. Cureus. 2018;10(5):e2690.

6. Enríquez de Salamanca J, Rus A, Díaz R, Gil R. Mano de barbero. Un nuevo caso. Actas Dermosifiliogr. 1987;78:775-7. 